\title{
PENGARUH CURRENT RATIO DAN DEBT TO EQUITY RATIO TERHADAP RETURN ON EQUITY PADA SUB SEKTOR OTOMOTIF
}

\author{
Nohita Cipta Nada \\ Universitas Singaperbangsa Karawang \\ 11ciptanadanohita@gmail.com, \\ Nanu Hasanuh \\ Universitas Singaperbangsa Karawang \\ ciptanadanohita@gmail.com,
}

\begin{abstract}
The purpose of this study was to determine whether there is an effect between the current ratio and the Debt on Equity Ratio on the Return on Equity in the Automotive and Component sub-sector companies listed on the Indonesia Stock Exchange for the 2015-2019 period. Purposive sampling technique is used as a sampling technique. There are 8 companies that meet the specified criteria. The type of data used is secondary data obtained from the Indonesia Stock Exchange website. The analytical method used is multiple linear regression analysis. This study shows the results that partially current ratio has no effect on ROE, while DER has a negative effect on ROE. Together, the current ratio and DER have an influence on $R O E$.
\end{abstract}

Keyword: Current Ratio, Debt on Equity, dan Return on Equity.

\section{PENDAHULUAN}

Pada umunya setiap perusahaan memiliki tujuan untuk mendapatkan laba yang tinggi. Perusahaan harus bisa mengembangkan kinerja perusahaan dengan baik agar laba yang dihasilkan bisa maksimal. Perusahaan yang memiliki laba tinggi, dapat mempengaruhi para investor untuk berinvestasi diperusahaan tersebut. Sebab dengan laba yang tinggi maka deviden yang akan didapatkan oleh para investor juga semakin tinggi, menurut (Risfa Jenia Argananta, 2020).

Rasio keuangan yang menggambarkan bagaimana kinerja perusahaan dalam memperoleh laba disebut rasio profitabilitas. Rasio ini merupakan rasio yang perlu diperhatikan, karena setiap perusahaan pastinya ingin mendapatkan keuntungan (laba) disetiap tahunnya agar bisa bertahan hidup. Jika perusahaan merugi, maka perusahaan akan sulit untuk menarik minat investor dan hal tersebut dalam mengakibatkan perusahaan kesulitan untuk mendapatkan modal dari luar (Sri Suartini dan Hari Silistiyo, 2017:110).

Sektor Otomotif merupakan salah satu sektor yang mampu mendorong perekonomian Indonesia. Sektor otomotif mampu menghasilkan produk ekspor unggulan sehingga dapat mendongkrak ekspor nasional. Dirjen ILMATE juga mengemukakan, jika dilihat dari pencapaian ekspor produk yang dilalukan sektor otomotif dan komponennya, terus menunjukan peningkatan (Kemenperin.go.id, 2019). Selain itu, sektor otomotif juga menjadi sektor yang banyak menyerap tenaga kerja di Indonesia. Pada tahun 2017 sektor otomotif mengalami kenaikan penyerapan tenaga kerja sebesar $13 \%$. Sehingga pada tahun 2017 sektor otomotif mampu menyerap tenaga kerja sebanyak 17,01 juta orang, yang sebelunya hanya 15,54 juta orang di tahun 2016 (Kompas.com, 2017).

Berdasarkan informasi yang diperoleh, menunjukan bahwa sektor otomotif mengalami pertumbuhan yang positif. Namun, meskipun 
demikian rasio profitabilitas yang dilihat dari return on equity pada sektor otomotif periode 2015-2019 mengalami pergerakan fluktuatif yang cencerung menurun. Return on equity digunakan untuk menilai kemampuan perusahaan dalam memperoleh laba dengan memanfaatkan ekuitas yang ada pada perusahaan. Jika ROE perusahaan mengalami peningkatan maka hal tersebut akan meningkatkan minat investor untuk mempertahankan atau menambah investasi pada perusahaan tersebut.

Disini peneliti ingin mencari tahu apa saja hal-hal yang mempengaruhi return on equity pada suatu perusahaan terutama pada pada sub sektor otomotif. Peneliti ingin menjadikan current ratio dan debt on equity ratio sebagai faktor yang dianggap mempengaruhi profitabilitas. Berikut ini merupakan data ROE, CR, dan DER sub sektor oromotif periode 20152019.

Tabel 1 ROE, CR dan DER Sub Sektor Otomotif

2015-2019

\begin{tabular}{lrrrrr}
\hline & $\mathbf{2 0 1 5}$ & $\mathbf{2 0 1 6}$ & $\mathbf{2 0 1 7}$ & $\mathbf{2 0 1 8}$ & $\mathbf{2 0 1 9}$ \\
\hline ROE & 0,040 & $-0,116$ & 0,157 & 0,053 & 0,075 \\
CR & 1,355 & 1,627 & 2,556 & 2,843 & 2,135 \\
DER & 1,231 & 2,048 & 0,966 & 1,078 & 1,131 \\
\hline
\end{tabular}

Dalam menganalisa pengaruh $\mathrm{CR}$ dan DER terhadap ROE, Anatu Nur Mawarni dan Gatot Kusjono (2021) menyatakan bahwa secara bersama-sama (simultan) CR dan DER berpengaruh terhadap ROE.

\section{KAJIAN PUSTAKA PENGEMBANGAN HIPOTESIS Current Ratio}

DAN

Menurut Sujarweni W.V. (2017:60) berpendapat bahwa current ratio adalah rasio yang dapat menilai seberapa likuid perusahaan tersebut dalam memenuhi kewajiban lancar menggunakan aset lancar dari perusahaan tersebut. Current ratio dapat diukur dengan cara membandingkan aset lancar dengan utang lancar yang ada pada laporan keuangan.

\section{Debt on Equity Ratio}

Menurut Kasmir

(2015:151)

mendefiniskan DER merupakan rasio keuangan yang memperlihatkan posisi keuangan suatu perusahaan. DER dijadikan rasio untuk mengukur liabilitas dengan modal. Untuk manghitung seberapa besar DER pada suatu perusahaan yaitu dengan membandingkan total utang dengan total modal yang ada pada laporan keuangan.

\section{Return on Equity (ROE)}

Menurut Agus S. Irfani, (2020:206), ROE merupakan rasio profitabilitas yang digunakan untuk mengetahui tingkat imbal hasil yang akan didapatkan oleh investor. Rasio ini juga digunakan untuk mengetahui sejauh mana perusahaan dapat memperoleh keuntungan dengan memanfaatkan modal yang dimilikinya. Rasio ini digunakan untuk melihat seberapa berhasil suatu entitas dalam mengelola modalnya. Untuk mengetahui seberapa besar rasio ini, yakni dengan membagi EAT dengan total ekuitas yang ada pada laporan keuangan.

\section{Pengaruh Current Ratio Terhadap Return on Equity}

Semakin besar current ratio pada suatu entitas hal ini mengartikan bahwa semakin kecil resiko kegagalan entitas dalam melunasi utang jangka pendeknya. Begitupun sebaliknya, jika nilai dar CR rendah, maka kinerja entitas dalam melunasi utang jangka pendeknya kurang baik. Dengan demikian, perusahaan yang tidak 
mampu memenuhi utang lancarnya dengan baik, akan mempengaruhi tingkat profitabilitas perusahaan sebab perusahaan akan dikenakan beban tambahan atas kewajibannya (Joko Tryono dan Rizka Hadya, 2020).

Pada, penelitian yang pernah dilakukan sebelumnya ada perbedaan hasil dan tidak konsisten. Joko Tryono dan Rizka Hadya (2020) menyatakan bahwa CR memiliki pengaruh positif terhadap ROE. Sedangkan pada penelitian Ratna Dumilah (2021) bependapat, CR memiliki pengaruh negarif terhadap ROE. Berbeda dengan penelitian yang dilakukan oleh Anatu Nur Mawarni dan Gatot Kusjono Rizki Adriani Pongrangga (2021) menyatakan bahwa CR tidak berpengaruh signifikan terhadap ROE.

H1: Current Ratio terhadap Return On Equity (ROE).

\section{Pengaruh Debt on Equity Ratio Terhadap Return on Equity}

Semakin tinggi nilai DER berarti menunjukkan utang yang punyai oleh suatu entitas lebih dibandingkan pada jumlah modalnya. Hal ini membuat semakin besar bula beban entitas kepada kreditur. Maka dengan demikian DER dianggap mempengaruhi tingkat profitabilitais perusahaan. Sebab, jumlah hutang yang dimiliki oleh perusahaan nantinya akan mengurangi jumlah laba yang diterima perusahaan (Kasmir, 2016).

Pada, penelitian terdahulu terdapat beberapa perbedaan hasil yang tidak konsisten. Henda Hendawati (2017) menyatakan bahwa DER berpengaruh positif terhadap ROE. Sedangkan pada penelittian Amalia Tiara Balqish (2020) menyatakan bahwa DER berpengaruh negatif terhadap ROE. Berbeda dengan Risfa Jenia Argananta (2017) berpendapat bahwa DER tidak berpengaruh signifikan terhadap ROE.

H2: Debt to Equity Ratio (DER) terhadap Return On Equity (ROE).

\section{Pengaruh Current Ratio dan Debt on Equity Ratio Terhadap Return on Equity}

Berdasarkan penelitian yang telah dilakukan sebelumnya, Anatu Nur Mawarni dan Gatot Kusjono (2021) menyatakan bahwa secara bersama-sama (simultan) $\mathrm{CR}$ dan DER memiliki pengaruh terhadap ROE. Sejalan Amalia Tiara Balqish (2020) yang juga menyatakan bahwa CR dan DER berpengaruh terhadap ROE. Dari kesamaan hasil tersebut, maka dapat ditarik kesimpulan jika CR dan DER dapat mempengaruhi tingkat ROE perusahaan.

H3: Current Ratio dan Debt to Equity Ratio (DER) terhadap Return On Equity (ROE).

\section{METODEPENELITIAN}

\section{Populasi dan Sampel}

Sampel dipilih menggunakan metode Purposive Sampling. Ada beberapa kriteria yang telah ditentukan dalam pemilihan sampel. Populasi yang digunakan dalam penelitian ini ialah perusahaan sub sektor otomotif dan komponen yang terdaftar di Bursa Efek Indonesia periode 2015-2019. Dari hasil pemilihan sampel terpilih 8 perusahaan. Data yang digunakan adalah data sekunder yang diperoleh dari situs Bursa Efek Indonesia.

Setelah memperoleh data yang diperlukan, peneliti mengolah data menggunakan SPPS 25. Peneliti melakukan uji asumsi klasik, agar data dianggap valid untuk memprediksi suatu masalah. Pertama dilakukan uji normalitas dengan uji kolmogorov-smirov test, dan diperoleh nilai Asymp. Sig. (2- tailed) 0,200. Karna >0,05 maka data yang digunakan berdistribusi normal. Kemudian uji autokorelasi, diperoleh nilai DW 2,198, $\mathrm{dl}=1,334$ dan $\mathrm{du}=$ 1,6589. Karna (4-d)>du maka tidak terjadi gejala auokorelasi pada model penelitian. Kemudian dilakukan uji multikolinearitas, dan diperoleh nilai Tolerance 0,763 dan VIF 1,311. Karnal nilai tolerance mendekti angka satu dan $\mathrm{VIF}<10$ maka tidak terjadi gejala multikolinieritas pada model penelitian. Selanjutnya pada uji hoteroskedastisitas, penyebaran titik-titik pada scatterplot tidak membentuk pola tertentu dan tersebar secara acak maka bahwa model yang 
digunakan terbebas dari gejaga heteroskedatisitas. Dari hasil uji asumsi klasik yang telah dilakukan, dapat diambil kesimpulan bahwa model regresi yang akan digunakan pada penelitian ini dianggap layak untuk dilakukan penelitian. (Rambat Lupiyonomdan Ridho Bramulya Ikhsan, 2015)

Setelah model dikatakan layak lalu yang terakhir, dilakukan uji hipotesis yang dilakukan baik secara simultan (uji f) serta secara pasrsial (uji t). Namun, Sebelum dilakukannya pengujian hipotesis, peneliti melakukan analisis deskriptif untuk mengetahui gambaran atau deskripsi suatu data.

\section{Metode Analisis Data}

Metode yang dipakai pada penelitian kali ini merupakan metode analisis regresi berganda. Menurut Rambat Lupiyoadi dan Ridho Bramulya Ikhsan (2015:138-139), Analisis regresi berganda merupakan analisis statistik yang menggabugkan dua variabel bebas dan variabel terikat.

$$
\mathrm{Y}=\alpha+\beta_{1} X_{1}+\beta_{2} X_{2}+e
$$

Keterangan:

$\begin{array}{ll}\mathrm{Y} & \text { : Return on Equity } \\ \mathrm{X}_{1} & \text { : Current Ratio } \\ \mathrm{X}_{2} & : \text { Debt on Equity Ratio } \\ \alpha & \text { : Konstanta } \\ \beta_{1}, \beta_{2} & \text { : Koefisian Regresi } \\ \mathrm{e} & \text { : Faktor Pengganggu Diluar Model }\end{array}$

\section{HASIL DAN PEMBAHASAN}

Sebelum dilakukan pengujian hipotesis peneliti melakukan analisis deskriptif terlebih dahulu untuk mendeskripsikan data yang telah diperoleh dengan melihat nilai min, max, maean, dan standar deviasi. Berikut hasil analisis statistik

Tabel 2 Statistik Deskriptif

\begin{tabular}{lrrrr}
\hline Variabel & \multicolumn{1}{c}{ Min } & \multicolumn{1}{c}{ Max } & Mean & St. Dev \\
\hline CR &, 00 & 7,93 & 2,1032 & 1,80031 \\
DER &, 07 & 8,26 & 1,2909 & 1,49852 \\
ROE & $-1,24$ &, 70 &, 0419 &, 24867 \\
\hline
\end{tabular}

Sumber: Data dioleh SPSS 25

Tabel 2 memperlihatkan bahwa current ratio mempunyai nilai minumun 0,00 dan nilai maksimum 7,93 dengan mean 2,1032 dan standar deviasi 1,80031 . DER mempunyai nilai minumun 0,07 serta nilai maksimum 8,26 dengan mean 1,2909 dan standar deviasi 1,49852. Sedangkan ROE mempunyai nilai minumun $-1,24$ dan nilai maksimum 0,70 dengan mean 0,0419 dan standar deviasi 0,24867 .

Tabel 3 Rangkuman Hasil Analisis Regresi Berganda

\begin{tabular}{lrrc}
\hline Hipotesis & t-statistik & \multicolumn{1}{c}{ Sign } & Ket \\
\hline (Constant) & 4,196 &, 000 & - \\
CR &,- 518 &, 608 & Ditolak \\
DER & $-7,129$ &, 000 & Diterima \\
Adjusted R- & & &, 627 \\
square & & \\
F-statistik & & & 31,218 \\
Sign & &, 000 \\
\hline Sumber: Data dioleh SPSS 25 &
\end{tabular}




\section{Pengaruh Current Ratio Terhadap Return on Equity}

Berdasarkan hasil uji parsial (uji t) yang terdapat pada tabel 3 , diperoleh nilai signifikasi 0,608 dikarenakan nilai sign >0,05 $(0,608>$ $0,05)$.

Dari hasil tersebut mengartikan bahwa $\mathrm{H} 1$ ditolak, maka pada penelitian ini diperoleh hasil bahwa Current Ratio tidak memiliki pengaruh yang signifikan terhadap Return on Equity pada sub sektor otomotif yang terdaftar di Bursa Efek Indonesia periode 2015-2019. Hasil penelitian ini sejalan dengan penelitian yang dilakukan oleh Anatu Nur Mawarni dan Gatot Kusjono Rizki Adriani Pongrangga dkk (2015) menyatakan bahwa CR tidak berpengaruh signifikan terhadap ROE.

\section{Pengaruh Debt on Equity Ratio Terhadap Return on Equity}

Dari hasil uji parsial yang terdapat pada tabel 3, diperoleh nilai signifikasi 0,000 dikarenakan nilai sign $<0,05(0,000<0,05)$ dan dengan nilai t hitung sebesar $-7,129$.

Dari hasil tersebut mengartikan bahwa $\mathrm{H} 2$ diterima, maka pada penelitian ini diperoleh hasil bahwa Debt on Equity Ratio memiliki pengaruh negatif yang signifikan terhadap Return on Equity pada sub sektor otomotif yang terdaftar di Bursa Efek Indonesia. Hasil penelitian ini sejalan dengan penelitian yang dilakukan oleh Amalia Tiara Balqish (2020) menyatakan bahwa DER berpengaruh negatif terhadap ROE.

\section{Pengaruh Current Ratio dan Debt on Equity Ratio Terhadap Return on Equity}

Dari hasil uji simultan yang terdapat pada tabel 3, diperoleh nilai signifikasi dapa uji $\mathrm{f}$ sebesar 0,000 dikarenakan nilai sign $<0,05$ $(0,000<0,05)$.

Dari hasil tersebut mengartikan bahwa $\mathrm{H} 3$ diterima, maka pada penelitian ini diperoleh hasil bahwa secara simultan Current Ratio dan Debt on Equity Ratio memiliki pengaruh yang signifikan terhadap Return on Equity pada sub sektor otomotif yang terdaftar di Bursa Efek Indonesia. Hal ini sejalan dengan penelitian yang dilakukan oleh Anatu Nur Mawarni dan Gatot Kusjono (2021) menyatakan bahwa secara bersama-sama (simultan) current ratio dan Debt to Equity Ratio (DER) berpengaruh terhadap Return On Equity (ROE).

\section{KESIMPULAN}

Pada penelitian kali ini dapat disimpulkan sebagi berikut. Pertama, Current Ratio tidak memiliki pengaruh yang signifikan terhadap Return on Equity. Maka setiap kenaikan atau penurunan current ratio tidak mempengaruhi hasil dari Return on Equity pada sub sektor otomotif yang terdaftar di Bursa Efek Indonesia. Kedua, Debt on Equity Ratio memiliki pengaruh negatif yang signifikan terhadap Return on Equity. Maka setiap kenaikan atau penurunan yang terjadi pada Debt on Equity Ratio akan berbanding terbalik dengan Return on Equity pada sub sektor otomotif yang terdaftar di Bursa Efek Indonesia. Ketiga, Secara simultan arau bersama sama Current Ratio dan Debt on Equity Ratio memiliki pengaruh yang signifikan terhadap Return on Equity pada sub sektor otomotif yang terdaftar di Bursa Efek Indonesia.

Penelitian ini masih memiliki banyak kekurangan dan keterbatasan. Tahun penelitian relatif singkat karna hanya melakukan penelitian 5 tahun dan Variabel yang diteliti hanya 2 (Current Ratio dan Debt on Equity Ratio), untuk penelitan selanjutnya diharapkan agar menambah waktu tahun penelitian dan menambahkan rasio keuangan perusahaan yang lainnya untuk dijadikan sebagai variabel penelitian. 


\section{DAFTAR PUSTAKA}

Argananta, R. J., \& Hidayat, I. (2017). ANALISIS PENGARUH CR, DER DAN TATO TERHADAP ROE PADA PT. MUSTIKA RATU TBK. Jurnal Ilmu Dan Riset Manajemen (Jirm), 6(10).

Balqish, A. T. (2020). Pengaruh CR dan DER terhadap ROE pada Perusahaan Perdagangan Eceran di BEI Periode 2015-2018. Owner: Riset dan Jurnal Akuntansi, 4(2), 657-666.

Dumilah, R. (2021). PENGARUH CURRENT RATIO DAN DEBT TO EQUITY RATIO TERHADAP RETURN ON EQUITY Survey pada Tobacco Manufacture Indonesia. JURNAL SeMaRaK, 1(1), 96-106.

Hendawati, H. (2017). Analisis Current Ratio, Debt to Equity Ratio dan Total Asset Turn Over Terhadap Return on Equity. Jurnal Sikap, 1(2), 97-111.

Irfani, Agus S. (2020). Manajemen Keuangan dan Bisnis, Teori dan Aplikasi. Jakarta: PT Gramedia Pustaka Utama.

Kasmir, 2016. Analisis Laporan Keuangan, Cetakan Ke-9, PT. Rajagrafindo Persada, Jakarta

Kasmir. 2015. Analisis Laporan Keuangan. Cetakan Kedelapan. PT Rajagrafindo Persada. Jakarta.

Lupiyoadi, Rambat dan Ridho Bramulya Ikhsan. (2015). Praktikum Metode Riset Bisnis. Jakarta: Salemba Empat.

Mawarni, A. N., \& Kusjono, G. (2021). Pengaruh Current Ratio dan Debt To Equity Ratio terhadap Return On Equity pada PT Pan Pacific Insurance, Tbk Tahun 20112018. Jurnal Disrupsi Bisnis: Jurnal Ilmiah Prodi Manajemen, Fakultas Ekonomi, Universitas Pamulang, 4(1), 76-85.

Sujarweni, W.V. (2017). Analisis Laporan Keuangan teori, aplikasi dan hasil penelitian.Yogyakarta:Pustaka Baru Press

Tryono, J., \& Hadya, R. (2020). Pengaruh Current Ratio, Debt To Equity Ratio, Working Capital Turn Over Terhadap Return On Equity Di D'Dhave Hotel Padang. Matua Jurnal, 2(1), 91-104.

https://www.idx.co.id/ https://www.kemenperin.go.id

https://www.otomotif.kompas.com/ 